\title{
TIRE-PAVEMENT COUPLING DYNAMIC SIMULATION UNDER TIRE HIGH-SPEED-ROLLING CONDITION
}

\author{
Wang, Y.., ${ }^{* *} ;$ Lu, Y. J. ; Si, C. D.* \& Sung, P.** \\ ${ }^{*}$ Key Laboratory of Traffic Safety and Control in Hebei, Shijiazhuang Tiedao University, \\ 17 Northeast, Second Inner Ring, Shijiazhuang, P. R. China \\ ${ }^{* *}$ School of Mechanical, Electronic, and Control Engineering, Beijing Jiaotong University, No. 3 \\ Shangyuancun, Beijing, P. R. China \\ *** Sun-Moon University, Chung Nam, Republic of Korea \\ E-Mail: wy@stdu.edu.cn
}

\begin{abstract}
The coupling effect between tire and pavement is an intensively researched subject to analyse the dynamic interaction of the vehicle-pavement system. By considering the $11.00 \mathrm{R} 20$ tire and expressway asphalt pavement, ABAQUS software was employed in this study to establish an improved model for simulating the coupling effect, in which the tire rubber was taken as a neoHookean material and the pavement was taken as a multilayer structure. The coupling was achieved by considering the equilibrium equation and continuity conditions of the contact surface. The tire rolling, which was modelled by the "steady-state transport" method provided by ABAQUS software, was imported to the tire-pavement coupling for the explicit dynamic computation. Numerical results indicate that the pavement deformation obviously weakens the tire vibration in comparison with the non-deformable assumption, in which the variance of the vertical acceleration at the tire centre is reduced by $25 \%$ and the power spectral density is decreased by $52 \%$. The influence of the horizontal contact stress (CSHEAR) is considered by taking different friction coefficients. Compared with the case without the CSHEAR, the stresses in the longitudinal and lateral directions within the contact area on the pavement surface are increased by approximately $45 \%$. This study simulates a more realistic situation, including the contact stress and high-speed-rolling tire, thus the conclusions provide a reference for the optimization and design of vehicles and pavement structures.

(Received in June 2015, accepted in December 2015. This paper was with the authors 2 months for 2 revisions.)
\end{abstract}

Key Words: Tire-Pavement Coupling System, Finite Element Method, Wheel Load, Dynamic Simulation

\section{INTRODUCTION}

With the development of the automobile technology and road transportation system, the high speed and heavy load capacity of vehicles, together with the interaction between vehicle and pavement, have become important topics in recent years. Extensive studies have been devoted to the analysis of dynamic coupling, and some meaningful results are achieved; however, a realistic coupling model considering the high-speed-rolling of the tire and $3 \mathrm{D}$ contact stress is still needed [1].

The analytical method, in which the vehicle is taken as a mass-spring model and the pavement as a beam on a foundation, is often used to analyse the coupling system. By taking the random field of the pavement surface as a stationary stochastic process, Sun [1] introduced a unified theory for analysing the vehicle-pavement interaction. Utilizing the Euler-Bernoulli beam on a Winkler foundation, Yang et al. [2] presented the transient response of the displacement under a moving load. Although a closed-form solution can be easily obtained for some specific cases, conducting an in-depth study for the coupling of subsystems is difficult.

The numerical simulation technology becomes an effective tool for solving the complex mechanical problems, which provides a new approach for the refined modelling of structures. 
Given that the vehicle-pavement coupling system has tremendous degrees of freedom, most existing simulations consider the modelling of the vehicle, tire, or pavement without coupling. The interaction of the vehicle-pavement system based on refined simulations remains at the developing stage.

\section{STATE OF THE ART}

The finite element method is extensively applied to solve the mechanical response of pavement structures. In pavement finite element models, the wheel load is assumed to be in simplified forms.

By assuming the wheel load to be a uniformly distributed static vertical stress, Kim et al. [3] analysed the influence of pavement design parameters on the orthotropic steel bridge deck performance, Kim and Lee [4] calculated the pavement responses in the base and subgrade course in association with the effects of multiple wheel/axle load interactions, and Ameri et al. [5] studied the mechanical properties of a cracked asphalt pavement.

To consider the short-term effect of the wheel load, Leonardi [6] applied a non-uniformly distributed cyclic load to a fixed position of the pavement in the rutting prediction of the airfield asphalt pavement. Compared with the static stress, this type of wheel load can deal with the short-term effect but fails to simulate the moving of the wheel load.

In the pavement dynamic response analysis, most models simplify the wheel load into a moving vertical stress. By applying this type of wheel load, Ambassa et al. [7] predicted the fatigue life of an asphalt pavement subjected to multiple axle loadings, Breakah and Williams [8] conducted a stochastic finite element analysis of the moisture damage in hot mix asphalt mixtures, and Ahmed et al. [9] analysed the combined effect of the asphalt concrete crossanisotropy and temperature variation on the pavement stress-strain.

Some studies have indicated that the axle load of vehicle is a random quantity and that the wheel load in the pavement finite element model should consider the random variation in the vehicle axle load. Khavassefat et al. [10], Sawant et al. [11], Lak et al. [12], and Patil et al. [13] established a vehicle-pavement coupling system model and realized a dynamic analysis of the vehicle-pavement coupling system by imposing a random moving load to the pavement. However, the wheel load in these studies was also simplified into a moving vertical stress.

The moving stress in the pavement model is closer to the practical situation than the fixed stress. However, the realistic wheel load is a 3D non-uniformly distributed moving load, which is rarely used in existing pavement finite element models. Al-Qadi and Wang [14], Dong et al. [15], and Hu and Walubita [16] used a 3D non-uniformly distributed moving load in the pavement mechanical response simulation, which fully represented the complexity of the wheel load.

Considerable researches have successfully conducted the tire structural mechanic analysis by the finite element method. In these studies, the pavement was simplified into a rigid body. Wang et al. [17, 18] and Yang et al. [19] accurately predicted the contact stress between tire and pavement under a steady-state condition by this model.

A few studies have been conducted on the tire-pavement coupling in recent years by the finite element model. Wang et al. [20,21] carried out an earlier research on the modelling of the tire-pavement coupling system and analysed the influence of the tire on the pavement rut and crack. Moslem and Hossein [22] analysed the tire-soil coupling, and the results were in agreement with the laboratory tests. The studies of references [20-22] did not consider the tire rotation. The tire-pavement coupling model established by Xia and Yang [23] simulated the tire rolling, and it was the first tire-pavement coupling model closest to the real prototype. However, the model established by Xia and Yang failed when the vehicle velocity was high. 
Consequently, this model could only simulate the quasi-static process of the interaction between tire and pavement.

The state of the art about the modelling and mechanical analysis of the tire-pavement coupling system indicates that the realization of the interaction between tire and pavement by the finite element method is a breakthrough for the coupling modelling. Finite element models of the tire-pavement coupling system presently cannot realize the high-speed-rolling of the tire and simulate the dynamic behaviours of the tire-pavement coupling system under the situation that the tire speed is close to the design speed of the road.

The remainder of this paper is organized as follows. Section 3 gives the mathematical description of the tire rolling by the finite element method and establishes the finite element models of the tire-pavement coupling system. By using the models established in Section 3, Section 4 simulates the tire-pavement coupling dynamic behaviour and analyses the influence of fast-rolling tire on the tire-pavement coupling system. Section 5 draws conclusions about the coupling effect between tire and pavement.

\section{METHODOLOGY}

\subsection{Computational domain}

In the tire-pavement coupling system modelled by this study, the prototype of the tire is an 11.00 R20 truck tire, with a section width of $293 \mathrm{~mm}$, an external diameter of $1,085 \mathrm{~mm}$, a single-tire load capacity of 3,000 kg, and a tire pressure of $0.72 \mathrm{MPa}$. For tire modelling, the prototype was simplified into the followings: (1) The difference in rubber materials was neglected. (2) The breaker belts and carcass were reserved. (3) The tire patterns were neglected, and the tire heating was not considered.

The tire model established on the basis of ABAQUS software is shown in Fig. 1. Tire rolling includes the angular velocity $\omega$ and linear velocity $v$, the rotation axis of $\omega$ is parallel to $Y$ axis, and the direction of $v$ is parallel to $X$ axis.

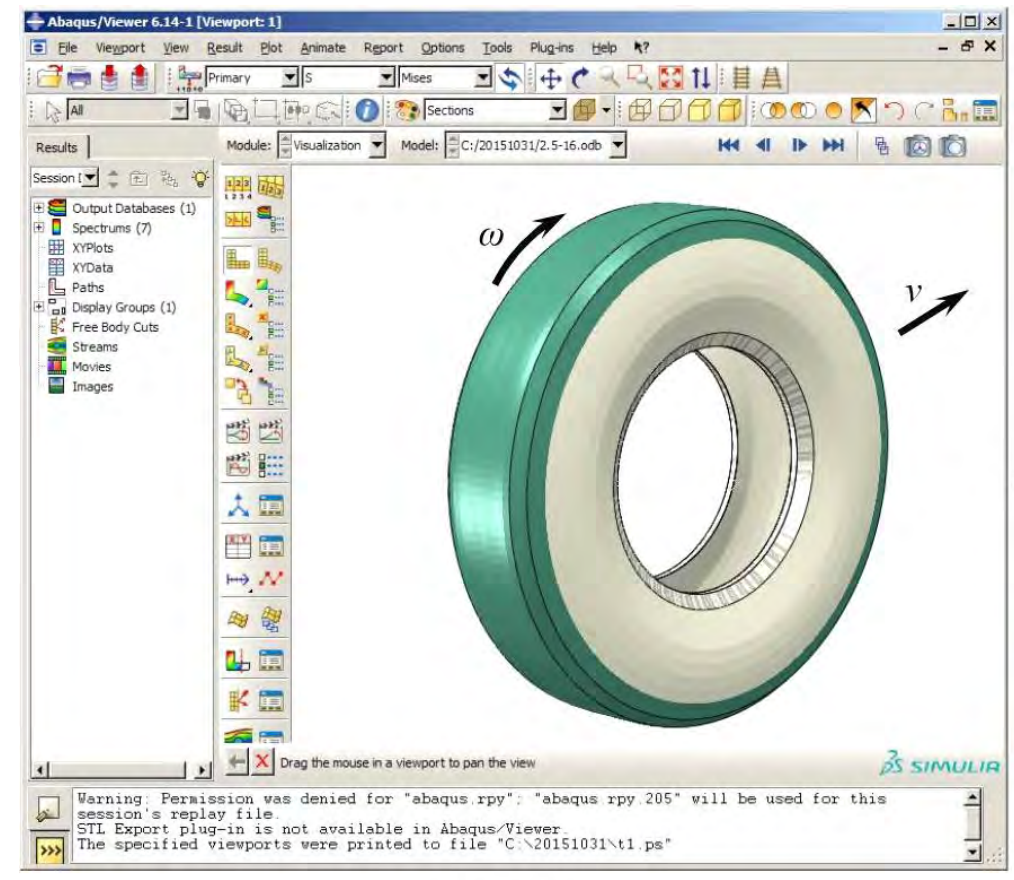

a) Full tire

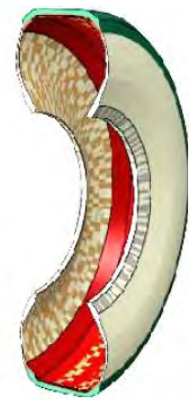

b) Sectional appearance of tire

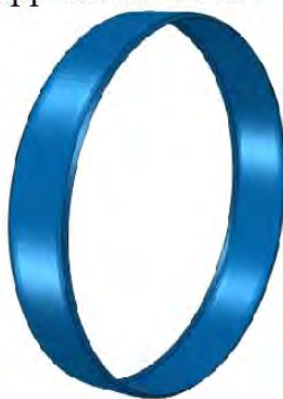

d) Breaker belt 1

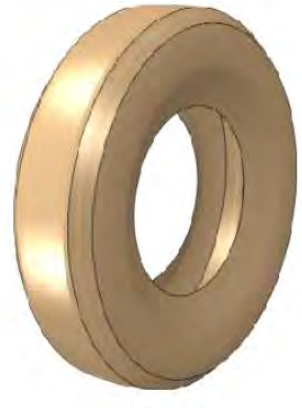

c) Carcass

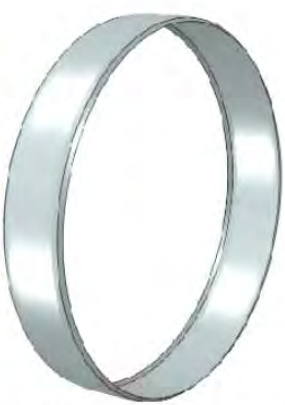

e) Breaker belt 2

Figure 1: Tire simulated by ABAQUS software. 
The pavement of the tire-pavement coupling system modelled in this study is an expressway pavement. During the modelling process, the pavement prototype was simplified as follows: (1) The pavement structure was simplified into four layers, and the displacement and deformation of materials were assumed to be the minimum. (2) The materials of different pavement layers were homogeneous, continuous, and isotropic. (3) Adjacent pavement layers were tightly bound without de-bonding failures.

The pavement model established on the basis of ABAQUS software is shown in Fig. 2. $X$ axis direction is the driving direction, $Y$ axis direction is the lateral direction of pavement, and the negative direction of $Z$ axis is the direction of depth. The solution efficiency was considered to determine the dimension of the pavement model with $X$ direction being $20 \mathrm{~m}, Y$ direction being $4 \mathrm{~m}$, and $Z$ direction being $5 \mathrm{~m}$.

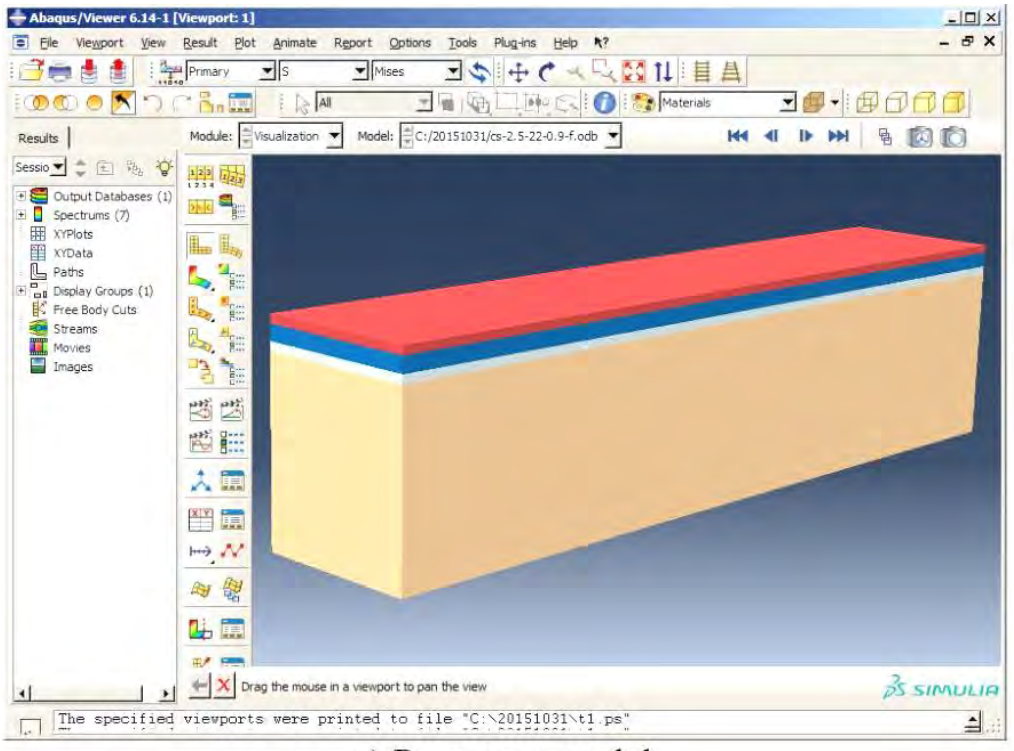

a) Pavement model

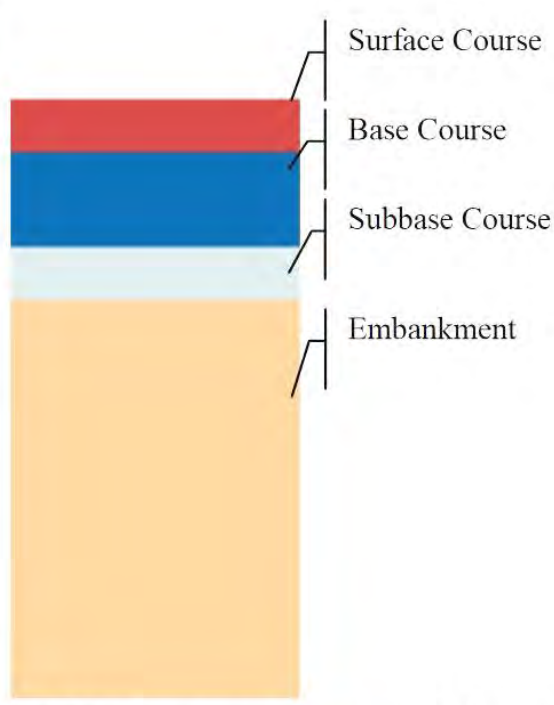

b) Thicknesses of pavement layers

Figure 2: Pavement simulated by ABAQUS software.

\subsection{Mathematical description of tire rolling by the finite element method}

To establish the tire-pavement coupling model, there are three non-linear problems to be solved simultaneously. The mathematical descriptions of the problems are as follows.

The rubber is a typical hyper-elastic material with an obvious non-linear elastic response. The polynomial model is used to describe the stress-strain relation of the rubber, and the general expression of this model is:

$$
U=\sum_{i+j=1}^{N} C_{i j}\left(\bar{I}_{1}-3\right)^{i}\left(\bar{I}_{2}-3\right)^{j}+\sum_{i=1}^{N} \frac{1}{D_{i}}\left(J_{\mathrm{el}}-1\right)^{2 i}
$$

where $U$ is the strain energy, $N$ is the polynomial order, $C_{i j}$ is the material parameter that describes the shear properties, $I_{1}$ and $I_{2}$ are the distortion measurements of materials, $J_{e l}$ is the bulk modulus, and $D_{i}$ is the material parameter that introduces the compressibility.

When $N=1$, Eq. (1) is rewritten into:

$$
U=C_{10}\left(\bar{I}_{1}-3\right)+C_{01}\left(\bar{I}_{2}-3\right)+\frac{1}{D_{1}}\left(J_{\mathrm{el}}-1\right)^{2}
$$

Eq. (2) is the Mooney-Rivlin material model.

When $\mathrm{C}_{01}=0$, Eq. (2) evolves into a neo-Hookean model, namely,

$$
U=C_{10}\left(\bar{I}_{1}-3\right)+\frac{1}{D_{1}}\left(J_{\mathrm{el}}-1\right)^{2}
$$


The Mooney-Rivlin and neo-Hookean models are the simplest constitutive models of hyper-elastic materials, and they can work well in the material characteristic simulation under small and medium strains.

Taking the undeformed situation of the finite element model as a measurement criterion, according to the virtual work principle, when $t+\Delta t$, the relationship between the GreenLagrange strain $E_{i j}$ of the structural deformation and the second Piola-Kirchhoff strain $S_{i j}$ is:

$$
\int_{0^{v}}^{t+\Delta t}{ }_{0} S_{i j} \delta^{t+\Delta t}{ }_{0} E_{i j} \mathrm{~d} v=\delta^{t+\Delta t} w
$$

The following can be obtained through varying the above equation:

$$
\int_{0^{v}}^{t+\Delta t}\left({ }_{0} S_{i j}+\Delta_{0} S_{i j}\right) \delta\left({ }_{0} E_{i j}+\Delta_{0} E_{i j}\right) \mathrm{d} w=\delta^{t+\Delta t} w
$$

The following is the matrix form of Eq. (5), which is the total Lagrangian finite element formulation for the geometrically non-linear analysis:

$$
\left([K]_{0}+[K]_{\sigma}+[K]_{L}\right)\{\delta q\}=\{F\}+\{T\}+\{P\}
$$

where $[K]_{0}$ is the tangent rigidity matrix, $[K]_{\sigma}$ is the stiffness matrix for geometric or initial stress, $[K]_{L}$ is the stiffness matrix for the large displacement or initial displacement, $\{\delta q\}$ is the displacement increment of node, $\{F\}$ is the body load, $\{T\}$ is the surface load, and $\{P\}$ is the equivalent stress of node.

The Lagrange multiplier method is selected to establish the equation of motion for the finite element model, and the following can be obtained from the virtual work principle and the functional variation method:

$$
\begin{gathered}
\Pi=\Pi_{\mathrm{u}}+\Pi_{\text {con }} \\
\delta \Pi=\delta \Pi_{\mathrm{u}}+\delta \Pi_{\mathrm{con}}=0
\end{gathered}
$$

where $\Pi$ is the total potential energy, $\Pi_{u}$ is the total potential energy that does not include contact constraint conditions, and $\Pi_{\text {con }}$ is the additional potential energy introduced with contact constraint conditions by the Lagrange multiplier method.

The equation set for the displacement vector and Lagrange multiplier can be obtained based on Eq. (8).

\subsection{Material parameters and boundary conditions}

The material parameters of the tire model are shown in Tables I and II, and the material parameters of the pavement model are shown in Table III.

Table I: Rubber material parameters of the tire model.

\begin{tabular}{|c|c|c|c|c|c|}
\hline \multirow{2}{P}{} & \multicolumn{2}{|c|}{ Parameters of the neo-Hookean model } & \multicolumn{3}{|c|}{ Parameters of the Prony series } \\
\cline { 2 - 6 }$\left(\mathrm{kg} / \mathrm{m}^{3}\right)$ & $\boldsymbol{C}_{\mathbf{0 1}}$ & $\boldsymbol{D}_{\mathbf{1}}$ & $\overline{\boldsymbol{g}}_{\boldsymbol{i}}^{\boldsymbol{P}}$ & $\overline{\boldsymbol{i}}_{\boldsymbol{i}}^{\boldsymbol{P}}$ & $\boldsymbol{\tau}_{\boldsymbol{i}}$ \\
\hline 1100 & $1.0 \mathrm{e} 6$ & $5.085 \mathrm{e}-6$ & 0.3 & 0.0 & 0.1 \\
\hline
\end{tabular}

Table II: Framework material parameters of the tire model.

\begin{tabular}{|l|c|c|c|}
\hline \multicolumn{1}{|c|}{ Material } & $\boldsymbol{\rho}\left(\mathrm{kg} / \mathrm{m}^{3}\right)$ & $\boldsymbol{E}(\mathrm{Pa})$ & $\boldsymbol{\mu}$ \\
\hline Breaker belt & 5900 & $1.722 \mathrm{e} 11$ & 0.3 \\
\hline Carcass & 1500 & $9.87 \mathrm{e} 9$ & 0.3 \\
\hline
\end{tabular}

Table III: Material parameters of the pavement model.

\begin{tabular}{|l|c|c|c|c|}
\hline Pavement layer & Thickness $(\mathrm{m})$ & $\boldsymbol{\rho}\left(\mathrm{kg} / \mathrm{m}^{3}\right)$ & $\boldsymbol{E}(\mathrm{Pa})$ & $\boldsymbol{\mu}$ \\
\hline Surface course & 0.20 & 2500 & $1.2 \mathrm{e} 9$ & 0.35 \\
\hline Base course & 0.36 & 2400 & $1.6 \mathrm{e} 9$ & 0.35 \\
\hline Subbase course & 0.20 & 1800 & $8.0 \mathrm{e} 8$ & 0.20 \\
\hline Embankment & 4.24 & 1850 & $3.0 \mathrm{e} 7$ & 0.40 \\
\hline
\end{tabular}


In the tire model, the rim was regarded as a rigid body, and the tire bead was attached to the rim. The displacement of the rim centre in $Y$ direction was 0 , and the displacements around $X$ and $Y$ directions were 0 . The displacements of the pavement in $X$ direction of the two sides perpendicular to $Y$ axis, in $Y$ direction of the two sides perpendicular to $X$ axis, and in $Z$ direction at the bottom were 0 .

\subsection{Modelling process and standard condition}

The modelling process of the tire-pavement coupling system is shown in Fig. 3. Finite element models of the tire and pavement were established on the basis of the finite element software ABAQUS, and a rigid plane was established to represent the non-deformable pavement.

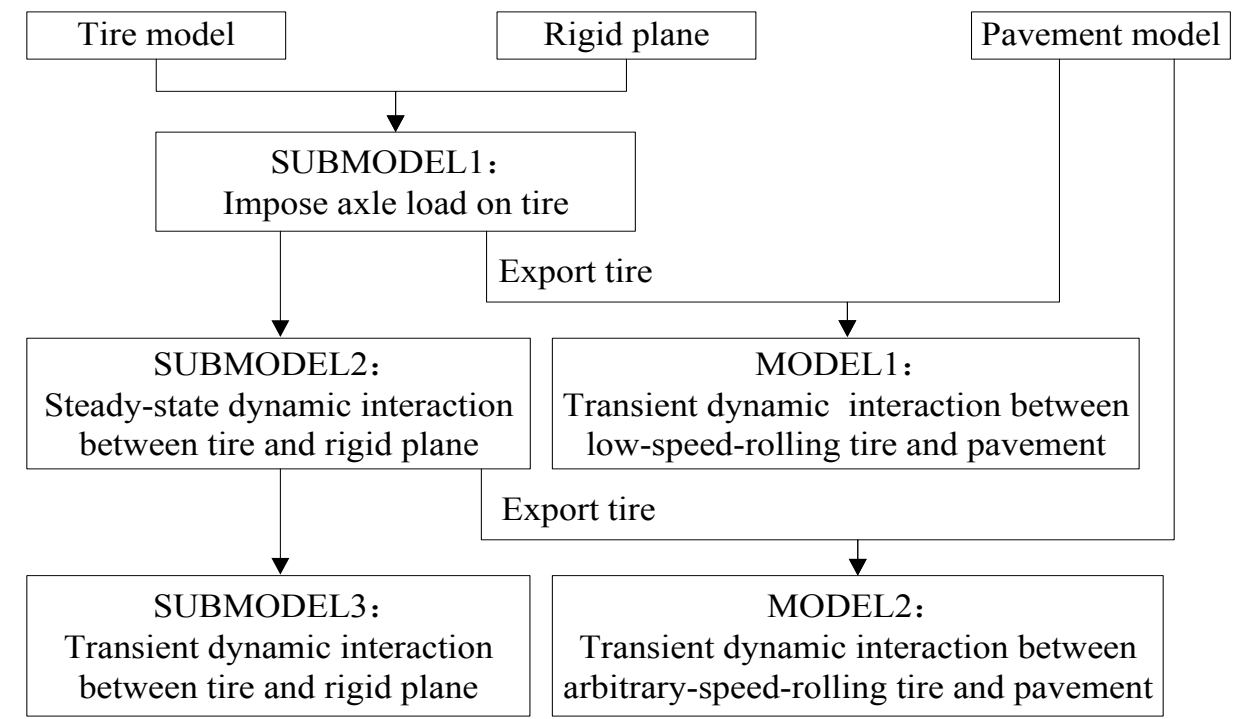

Figure 3: Modelling process of the tire-pavement coupling system.

SUBMODEL1 can be established by invoking the tire and non-deformable pavement to one model, setting the contact relationship for them, and imposing the axle load in the negative direction of $Z$ axis on the rim centre. Based on SUBMODEL1, SUBMODEL2 was obtained by using the "steady-state transport" method of ABAQUS software to model the steady-state dynamic interaction between tire and rigid plane. The "result transfer capability" function of ABAQUS software was used to import the results from SUBMODEL2 to SUBMODEL3, by which the transient rolling can be simulated.

MODEL1 can be obtained by invoking the deformed tire model of SUBMODEL1 and the pavement model into one model and setting the contact relationship for them. The interaction between tire and deformable pavement can be simulated by MODEL1, which has been verified and applied in reference [23]. The tire in MODEL1 can be rolled at a low speed only by imposing boundary conditions at the tire centre.

MODEL 2 can be obtained by invoking the deformed tire model of SUBMODEL2 and the pavement model into one model and setting the contact relationship for them. The tire in MODEL2 can be set to an arbitrary linear velocity and an angular velocity at the initial moment without imposing boundary conditions at the tire centre.

The axle load for the pavement design (100 kN single axle load with dual wheel) and the common speed of trucks in expressway were referred to determine the standard condition. Dual wheel was selected to determine the tire operation parameters. The distance between two tires was $346 \mathrm{~mm}$, the single-tire axle load was $25 \mathrm{kN}$, and the tires were operated under a free rolling condition with a linear velocity of $80 \mathrm{~km} / \mathrm{h}$. The pavement was assumed to be a 
newly constructed asphalt concrete pavement with the friction coefficient $f$ being 0.9. Fig. 4 shows the results simulated by MODEL2 under the standard condition.

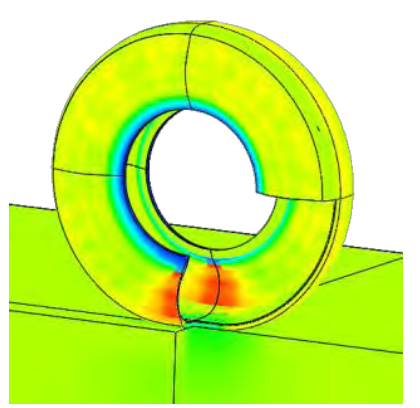

a) Tire-pavement interaction at $t=0.0 \mathrm{~s}$

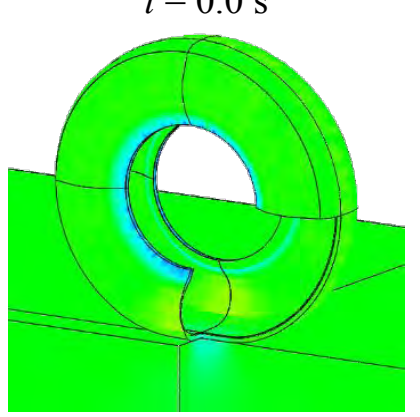

d) Tire-pavement interaction at $t=0.6 \mathrm{~s}$

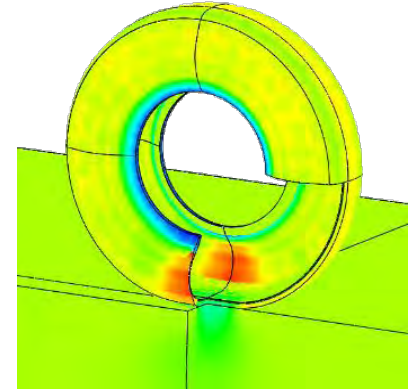

b) Tire-pavement interaction at $t=0.2 \mathrm{~s}$

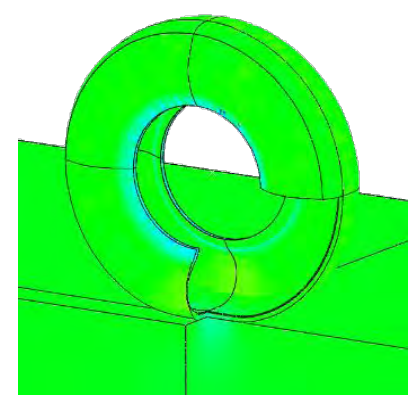

e) Tire-pavement interaction at $t=0.8 \mathrm{~s}$

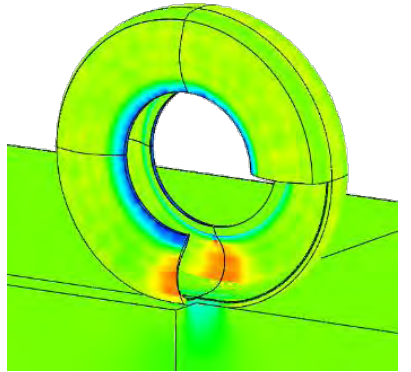

c) Tire-pavement interaction at $t=0.4 \mathrm{~s}$

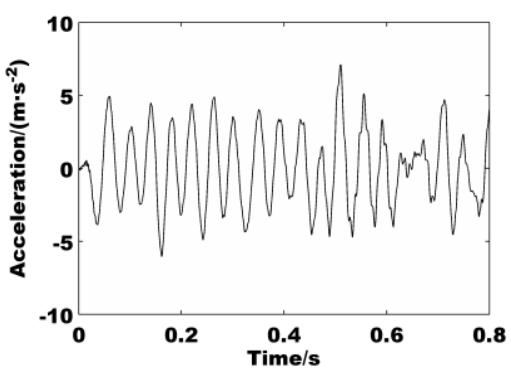

f) Vertical acceleration of the tire center

Figure 4: Tire-pavement interactions under the standard condition.

\section{RESULT ANALYSIS AND DISCUSSION}

\subsection{Tire-pavement contact stress}

SUBMODEL2 is a typical model for the tire-pavement contact stress prediction. In this study, the simulation results of this model were used to quantitatively evaluate the distribution features of the tire-pavement contact stress and as a basis of checking whether MODEL2 can impose the complicated contact stress between tire and pavement. SUBMODEL2 and MODEL2 were used to simulate the tire-pavement contact stress under the standard condition, and the simulation results are shown in Figs. 5-7.

The simulation results of SUBMODEL2 show that when the tire is under a free rolling condition at a speed of $80 \mathrm{~km} / \mathrm{h}$, the pavement is subjected to the complicated contact stress. The vertical contact stress (CPRESS) is uniformly distributed in a nearly circular area of tire. Except the margin, the CPRESS of most regions in the tire footprint is approximate to the tire pressure $(0.72 \mathrm{MPa})$ in numerical value. The horizontal contact stresses (CSHEAR) are relatively complicated, and their distributions in the tire footprint are not uniform. Their values also do not have a direct relationship with the tire pressure. The CSHEAR in $X$ direction (CSHEAR1) is symmetrically distributed at left and right, whereas the CSHEAR in $Y$ direction (CSHEAR2) is anti-symmetrically distributed at left and right.

When tire is operated under a free rolling condition, the resultant force of the CSHEAR1 is equal to the rolling resistance of the tire. For a newly constructed asphalt concrete pavement, $f$ is 0.012 . When a single tire is under an axle load of $25 \mathrm{kN}$, the rolling resistance is only $300 \mathrm{~N}$. Similarly, under a free rolling condition, the resultant force of the CSHEAR2 is 0 . The magnitude orders of the CSHEAR1 and CSHEAR2 resultant forces are far less than that of the axle load under a free rolling condition. Hence, in the traditional pavement 
mechanic analysis, the wheel load is simplified into a $0.70 \mathrm{MPa}$ circular uniformly distributed vertical stress. This type of wheel load is approximate to the CPRESS calculated by SUBMODEL2. Nevertheless, the extreme values of the CSHEAR are $25 \%-30 \%$ of that of CPRESS. Only from the difference between the magnitude orders of the CSHEAR and CPRESS, the CSHEAR in the pavement finite element model should not be neglected.

The comparison of the contact stress simulation results of MODEL2 and SUBMODEL2 indicates that the spatial distribution and numerical values of the tire-pavement contact stress are basically identical and thus, MODEL2 can impose the three-way non-uniformly distributed stress between tire and pavement. To change operation conditions, such as the tire pressure, axle load, angular velocity, linear velocity, etc., when necessary, it is only needed to re-import the calculation results into MODEL2 after changing the corresponding parameters in SUBMODEL1 and SUBMODEL2.

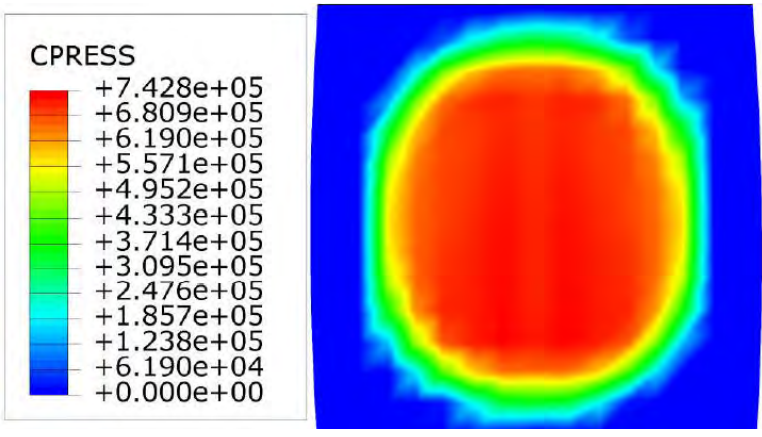

a) SUBMODEL2 simulation result

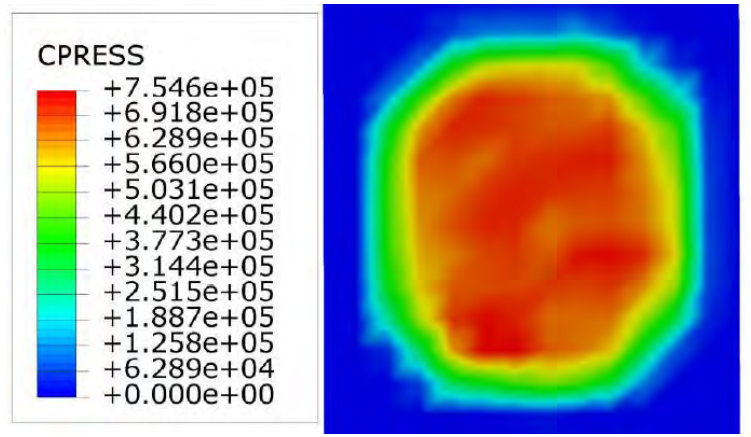

b) MODEL2 simulation result

Figure 5: Simulation results of the vertical contact stress.

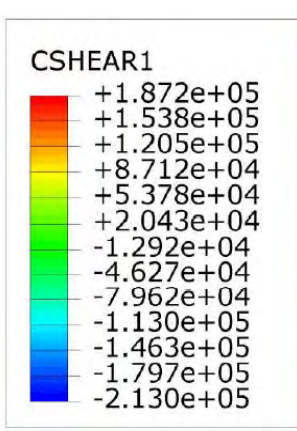

a) SUBMODEL2 simulation result

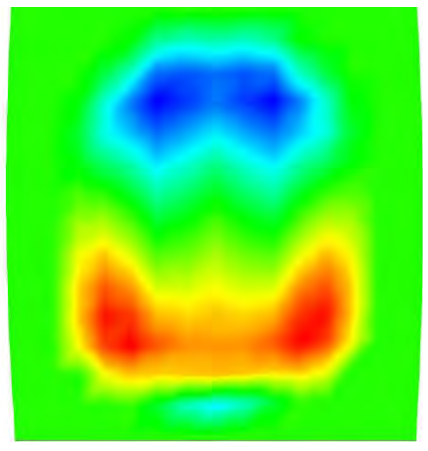

Figure 6: Simulation results of the longitudinal contact stress.

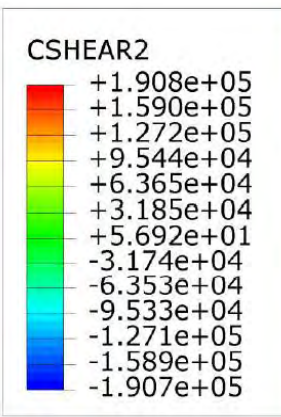

a) SUBMODEL2 simulation result

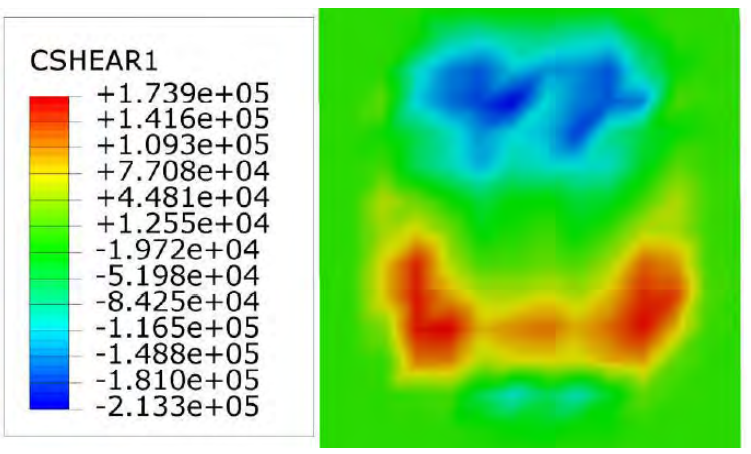

b) MODEL2 simulation result

Figure 7: Simulation results of the lateral contact stress. 


\subsection{Tire vibration}

The parameters of the tires in both MODEL2 and SUBMODEL3 at the initial moment, such as $\omega, v$, and pre-deformation, were imported from SUBMODEL2, and this processing method resulted in the tire vibration. To evaluate the influence of pavement deformation on the tire dynamic behaviour, MODEL2 and SUBMODEL3 were used to conduct the simulation of the standard condition. The simulation results of vertical acceleration at the tire centre were extracted, and their time history and power spectral density (PSD) are shown in Figs. 8 and 9, respectively.

SUBMODEL3 simplifies the pavement into a rigid body. The pavement surface is an ideal horizontal plane without the random excitation of pavement unevenness to the tire. Hence, the tire vibration is quite uniform, the power spectral component of the acceleration is relatively simple, and the tire vibration is similar to a persistent oscillation motion. The mean vertical acceleration of tire is $-0.0016 \mathrm{~m} / \mathrm{s}^{2}$, the variance of vertical acceleration is 3.5303 $\mathrm{m}^{2} / \mathrm{s}^{4}$, and the acceleration PSD has a peak value at $7.863 \mathrm{~Hz}$, with its amplitude being 6.202.

The pavement in MODEL2 is a flexible body, and the surface is also an ideal horizontal plane. The comparison of the simulation results of MODEL2 and SUBMODEL3 implies that the pavement deformation has a significant influence on the tire vibration. Compared with that in SUBMODEL3, the tire motion in MODEL2 is complicated, and the period component in the dynamic response is greatly weakened. As the pavement absorbs part of the vibration energy, the tire vibration amplitude is reduced. The mean vertical acceleration of the tire is $-0.0399 \mathrm{~m} / \mathrm{s}^{2}$, the variance of the vertical acceleration is $2.6462 \mathrm{~m}^{2} / \mathrm{s}^{4}$, and the peak value of the acceleration PSD is also at $7.863 \mathrm{~Hz}$, but its amplitude is reduced to 2.932 .

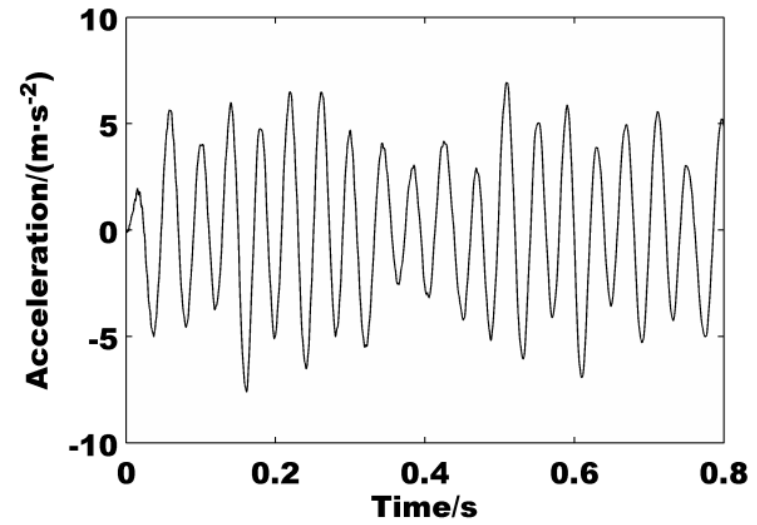

a) SUBMODEL3 simulation result

Figure 8: Time history of the vertical acceleration.

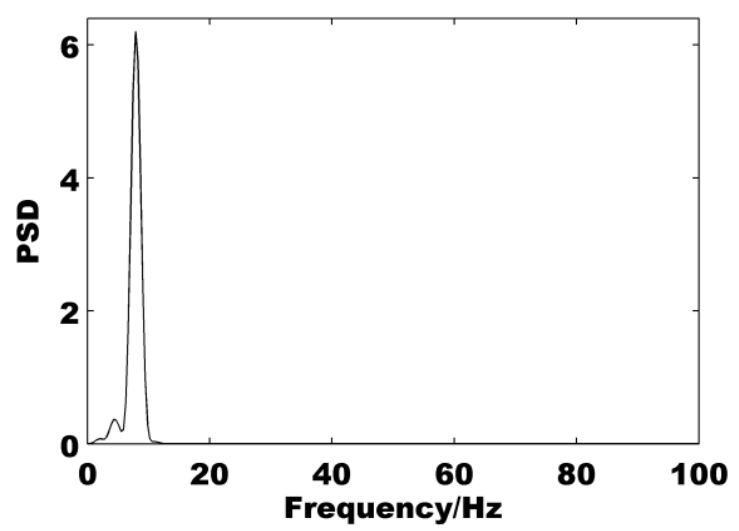

a) SUBMODEL3 simulation result

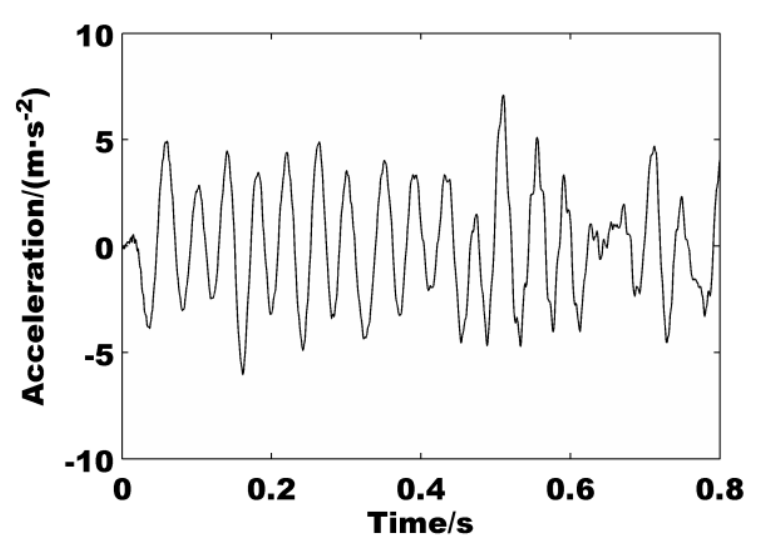

b) MODEL2 simulation result

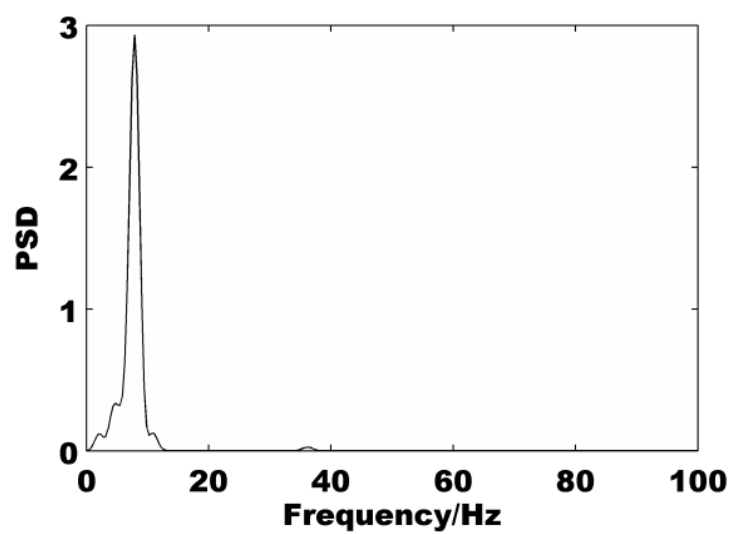

b) MODEL2 simulation result

Figure 9: PSD of the vertical acceleration. 


\subsection{Pavement response}

MODEL2 was applied to conduct the simulation twice to evaluate the influence of the CSHEAR on the pavement response. One of the simulations was conducted under the standard condition. In the other simulation, $f$ of pavement was set as 0.0 , which was approximated to represent the effect of moving circular uniformly distributed vertical stress on the pavement. The pavement normal stresses of the two simulations were extracted, as shown in Figs. 10-12.

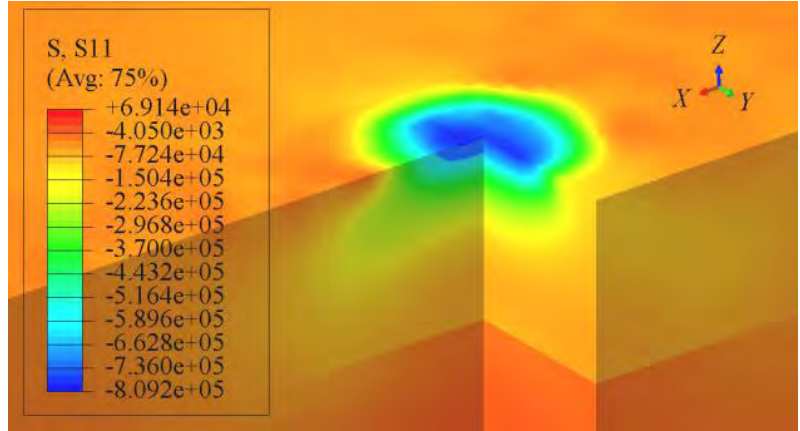

a) $f=0.9$

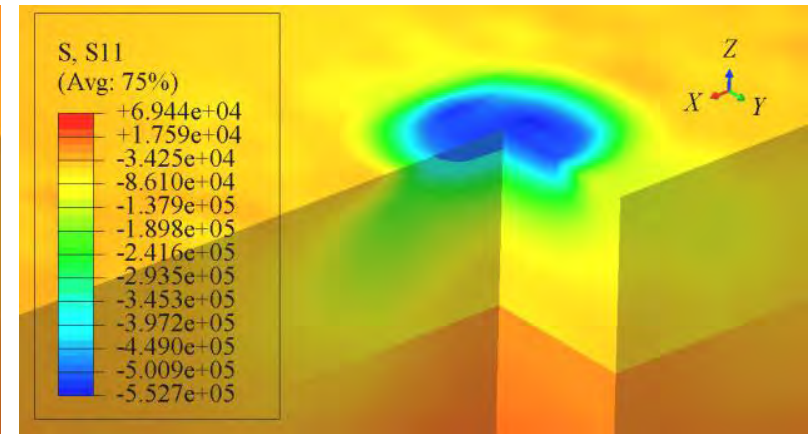

b) $f=0.0$

Figure 10: Simulation results of the normal stress in the longitudinal direction.

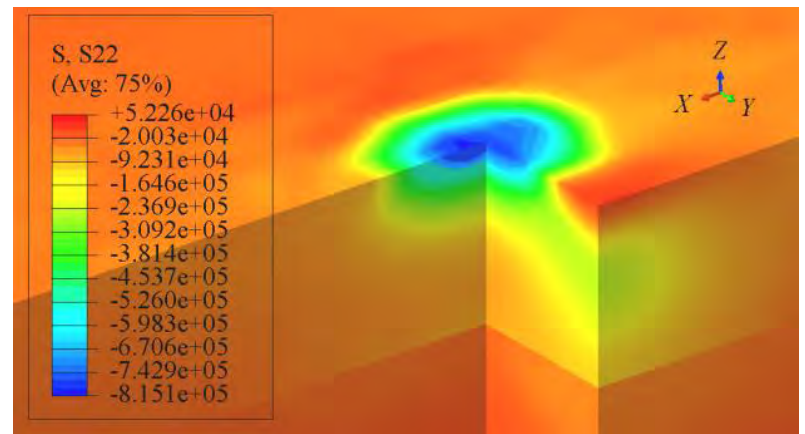

a) $f=0.9$

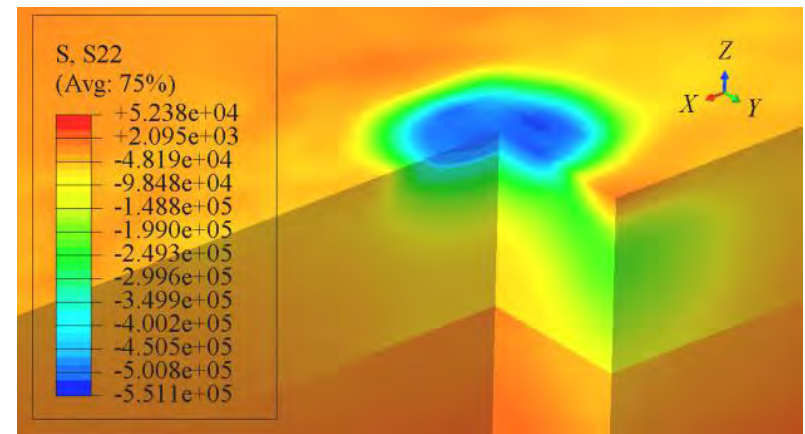

b) $f=0.0$

Figure 11: Simulation results of the normal stress in the lateral direction.

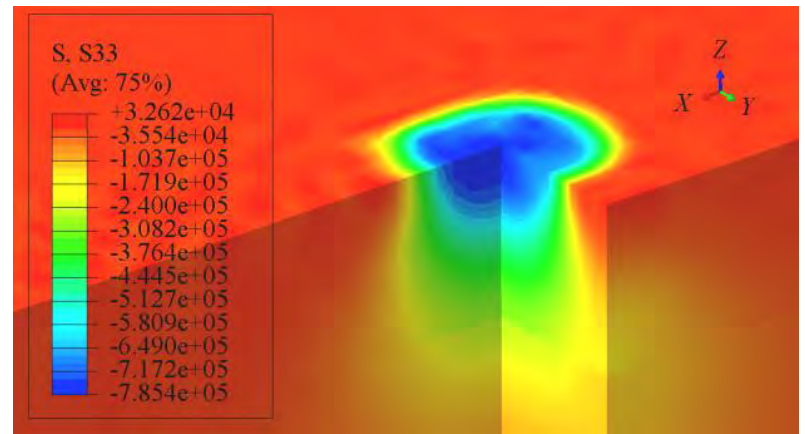

a) $f=0.9$

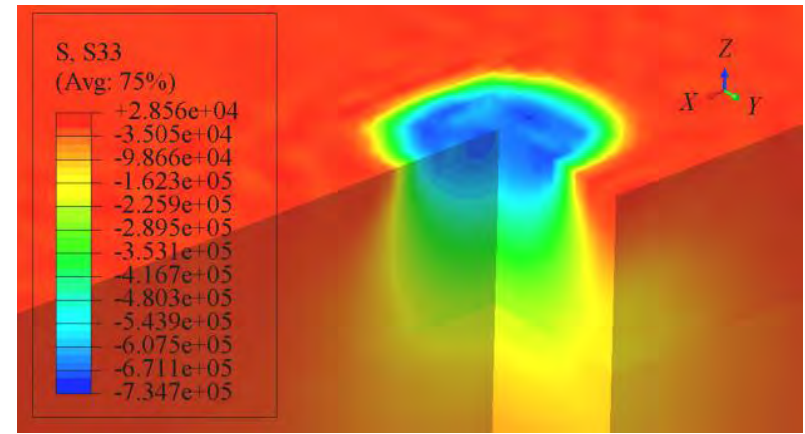

b) $f=0.0$

Figure 12: Simulation results of the normal stress in the vertical direction.

From the pavement response, the influence of the CSHEAR on the deeper layers of pavement is limited. Except the surface course, regardless of whether CSHEAR is imposed, the normal stress in the same position of pavement has no obvious difference. Hence, taking a moving circular uniformly distributed vertical stress as the wheel load can lead to an accurate prediction of the mechanical behaviour for layers below the surface course. 
The CSHEAR has an obvious influence on the mechanical response of the surface course; the closer it is to the pavement surface, the more significant influence of the CSHEAR will be. When the CSHEAR is not considered, the normal stress in the vertical direction (S33) on the pavement surface is close to the CPRESS, i.e., approximately $0.73 \mathrm{MPa}$. The spatial distributions of the normal stress in the longitudinal direction (S11) and the normal stress in the lateral direction (S22) are largely the same as that of the S33, and the extreme values are approximately $75 \%$ of that of the S33. After the CSHEAR is considered, the spatial distributions of normal stresses on the pavement surface do not have an obvious change, and so does the value of the S33. However, when compared with the situation in which the CSHEAR is not considered, the CSHEAR makes the S11 and S22 increase obviously in values. Their extreme values are increased by over $45 \%$, which are nearly equal to that of S33. Owing to the CSHEAR effect, micro-cracks are easily generated in the asphalt surface course. With an increase in the wheel load repetition, micro-cracks will further develop into pavement distresses, such as pothole or loose, etc. Hence, when predicting the early-age damage in an asphalt surface course, the CSHEAR must be considered.

\section{CONCLUSIONS}

To accurately evaluate the coupling dynamic behaviour between the high-speed-rolling truck tire and the expressway pavement, an improved 3D coupling finite element model was established to simulate the mechanical behaviour of the tire-pavement coupling system, in which tires were operated under a free rolling condition with a linear velocity of $80 \mathrm{~km} / \mathrm{h}$. The following conclusions can be drawn from this study:

(1) The improved tire-pavement coupling model (MODEL2) can be established by importing the steady-state rolling tire and pavement into one model and setting the contact relationship between them. The tire in the MODEL2 can be accelerated, decelerated, or freely rolled at an arbitrary initial speed.

(2) When an 11.00R20 tire is under a free rolling condition with a linear velocity of 80 $\mathrm{km} / \mathrm{h}$, the complicated three-way non-uniformly contact stress exists between tire and pavement. The CPRESS is uniformly distributed in a nearly circular area, and its value is approximate to the tire pressure. The CSHEAR1 is symmetrically distributed at left and right, whereas the CSHEAR2 is anti-symmetrically distributed at left and right. Their values do not have a direct relationship with the tire pressure.

(3) MODEL2 imposes a three-way non-uniformly distributed moving wheel load to the pavement. The simulation results show that under the standard condition, the CSHEAR has a great influence of the mechanical behaviour on the pavement surface course. The closer it is to the pavement surface, the greater influence of the CSHEAR will be; to the greatest extent, it can make the S11 and S22 increase by over $45 \%$ when compared with the situation in which the CSHEAR is not considered. Hence, in predicting the early-age damage for a pavement surface course, the CSHEAR must be fully considered.

(4) The vibration phenomenon happens during the rolling process of the tire. If the pavement is simplified into a rigid body, then the tire vibration will be approximated as a persistent oscillation motion. The results simulated by MODEL2 indicate that the pavement deformation exerts a significant influence on the tire vibration, the period component in the dynamic response of the tire is weakened by a large margin, and the vibration amplitude of tire is also reduced.

The research results can provide a reference for optimizing the vehicle and pavement structure. This research, however, does not analyse the influence of tire pattern and pavement random excitation on the dynamic behaviour of the tire-pavement coupling system. According to the actual status of a real prototype, the further study can introduce the tire pattern and 
pavement random excitation to conduct a refined analysis of the tire-pavement coupling dynamic behaviours for different rolling speeds of the tire and different friction coefficients of the pavement.

\section{ACKNOWLEDGMENTS}

This study was supported by the National Natural Science Foundation of China for the financial support (Grant Nos. 11302138, 11172183, and 11102121).

\section{REFERENCES}

[1] Sun, L. (2013). An overview of a unified theory of dynamics of vehicle-pavement interaction under moving and stochastic load, Journal of Modern Transportation, Vol. 21, No. 3, 135-162, doi: $10.1007 / \mathrm{s} 40534-013-0017-8$

[2] Yang, S.; Chen, L.; Li, S. (2015). Dynamics of vehicle-road coupled system, Springer-Verlag, Berlin

[3] Kim, T. W.; Baek, J.; Lee, H. J.; Lee, S. Y. (2014). Effect of pavement design parameters on the behaviour of orthotropic steel bridge deck pavements under traffic loading, International Journal of Pavement Engineering, Vol. 15, No. 5, 471-482, doi:10.1080/10298436.2013.839790

[4] Kim, M.; Lee, J. H. (2011). Study on nonlinear pavement responses of low volume roadways subject to multiple wheel loads, Journal of Civil Engineering and Management, Vol. 17, No. 1, 45-54, doi:10.3846/13923730.2011.554012

[5] Ameri, M.; Mansourian, A.; Heidary Khavas, M.; Aliha, M. R. M.; Ayatollahi, M. R. (2011). Cracked asphalt pavement under traffic loading - A 3D finite element analysis, Engineering Fracture Mechanics, Vol. 78, No. 8, 1817-1826, doi:10.1016/j.engfracmech.2010.12.013

[6] Leonardi, G. (2015). Finite element analysis for airfield asphalt pavements rutting prediction, Bulletin of the Polish Academy of Sciences: Technical Sciences, Vol. 63, No. 2, 397-403, doi:10.1515/bpasts-2015-0045

[7] Ambassa, Z.; Allou, F.; Petit, C.; Eko, R. M. (2013). Fatigue life prediction of an asphalt pavement subjected to multiple axle loadings with viscoelastic FEM, Construction and Building Materials, Vol. 43, 443-452, doi:10.1016/i.conbuildmat.2013.02.017

[8] Breakah, T. M.; Williams, R. C. (2015). Stochastic finite element analysis of moisture damage in hot mix asphalt, Materials and Structures, Vol. 48, No. 1, 93-106, doi:10.1617/s11527-013$\underline{0170-\mathrm{x}}$

[9] Ahmed, M. U.; Rahman, A.; Islam, M. R.; Tarefder, R. A. (2015). Combined effect of asphalt concrete cross-anisotropy and temperature variation on pavement stress-strain under dynamic loading, Construction and Building Materials, Vol. 93, 685-694, doi:10.1016/ j.conbuildmat.2015.06.031

[10] Khavassefat, P.; Jelagin, D.; Birgisson, B. (2015). Dynamic response of flexible pavements at vehicle-road interaction, Road Materials and Pavement Design, Vol. 16, No. 2, 256-276, doi:10.1080/14680629.2014.990402

[11] Sawant, V. A.; Patil, V. A.; Deb, K. (2011). Effect of vehicle-pavement interaction on dynamic response of rigid pavements, Geomechanics and Geoengineering: An International Journal, Vol. 6, No. 1, 31-39, doi:10.1080/17486025.2010.521591

[12] Lak, M. A.; Degrande, G.; Lombaert, G. (2011). The effect of road unevenness on the dynamic vehicle response and ground-borne vibrations due to road traffic, Soil Dynamics and Earthquake Engineering, Vol. 31, No. 10, 1357-1377, doi:10.1016/j.soildyn.2011.04.009

[13] Patil, V. A.; Sawant, V. A.; Deb, K. (2013). 3D finite-element dynamic analysis of rigid pavement using infinite elements, International Journal of Geomechanics, Vol. 13, No. 5, 533544, doi:10.1061/(ASCE)GM.1943-5622.0000255

[14] Al-Qadi, I. L.; Wang, H. (2011). Prediction of tire pavement contact stresses and analysis of asphalt pavement responses: A decoupled approach, Journal of the Association of Asphalt Paving Technologists, Vol. 80, 289-316

[15] Dong, Z.; Tan, Y.; Ou, J. (2013). Dynamic response analysis of asphalt pavement under threedirectional nonuniform moving load, China Civil Engineering Journal, Vol. 46, No. 6, 122-130 
[16] Hu, X.; Walubita, L. F. (2011). Modeling mechanistic responses in asphalt pavements under three-dimensional tire-pavement contact pressure, Journal of Central South University of Technology, Vol. 18, No. 1, 250-258, doi:10.1007/s11771-011-0687-5

[17] Wang, H.; Al-Qadi, I. L.; Stanciulescu, I. (2014). Effect of surface friction on tire-pavement contact stresses during vehicle maneuvering, Journal of Engineering Mechanics, Vol. 140, No. 4, Paper No. 04014001, doi:10.1061/(ASCE)EM.1943-7889.0000691

[18] Wang, H.; Al-Qadi, I. L.; Stanciulescu, I. (2012). Simulation of tyre-pavement interaction for predicting contact stresses at static and various rolling conditions, International Journal of Pavement Engineering, Vol. 13, No. 4, 310-321, doi:10.1080/10298436.2011.565767

[19] Yang, J.-S.; Ong, G. P.; Fwa, T. F.; Chew, C. H. (2011). Modeling the effect of rolling conditions on stress development at tire-pavement contact patch, Proceedings of the Eastern Asia Society for Transportation Studies, Vol. 8, Paper No. 253, 14 pages, doi:10.11175/eastpro.2011.0.253.0

[20] Wang, G.; Roque, R. (2010). Three-dimensional finite element modeling of static tire-pavement interaction, Transportation Research Record, Vol. 2155, 158-169, doi:10.3141/2155-17

[21] Wang, G.; Roque, R.; Morian, D. (2012). Effects of surface rutting on near-surface pavement responses based on a two-dimensional axle-tire-pavement interaction finite-element model, Journal of Materials in Civil Engineering, Vol. 24, No. 11, 1388-1395, doi:10.1061/ (ASCE)MT.1943-5533.0000526

[22] Moslem, N.; Hossein, G. (2014). Numerical simulation of tire/soil interaction using a verified 3D finite element model, Journal of Central South University, Vol. 21, No. 2, 817-821, doi:10.1007/s11771-014-2005-5

[23] Xia, K.; Yang, Y. (2012). Three-dimensional finite element modeling of tire/ground interaction, International Journal for Numerical and Analytical Methods in Geomechanics, Vol. 36, No. 4, 498-516, doi:10.1002/nag.1018 